\title{
Towards a balanced 3D kinematic model of a faulted domain - the Bergheim open pit mine, Lower Rhine Basin
}

\author{
A. Thomsen ${ }^{1} \&$ A. Siehl ${ }^{1,2}$ \\ 1 Geologisches Institut, Bonn University, Nußallee 8, 53115 Bonn, Germany \\ 2 corresponding author; e-mail: siehl@uni-bonn.de
}

Manuscript received: December 2000; accepted: January 2002

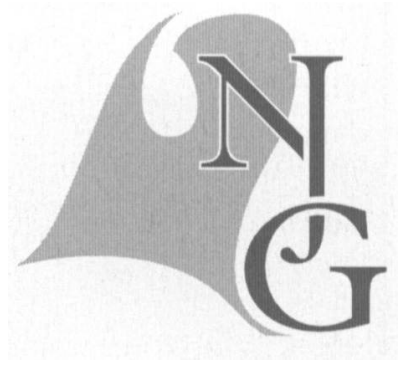

\begin{abstract}
In the context of the investigation of the sedimentary and structural evolution of the Cenozoic Lower Rhine Basin, the construction of a volume-balanced kinematic model of a small faulted domain with detailed spatial information on strata and fault geometry from a set of parallel geological sections is under development. A 3D geometry model is built that allows for relative movements of blocks at fault surfaces. Rouby's method of restoration in the map plane is used to determine horizontal displacement fields. The 3D and $3 \mathrm{D}(\mathrm{t})$ geometry models are supported by the object-oriented geometry database tool GeoToolKit for storage and retrieval of selected parts of the model using queries referring to spatial and temporal criteria, while visualization is based on key frame technique.
\end{abstract}

Keywords: balanced kinematic restoration, Bergheim lignite mine, object-oriented database, Rouby's method, geological space-time models.

\section{Introduction}

A joint project of geologists and computer scientists at Bonn University deals with the development of database-supported space-time models of the sedimentary and structural evolution of the Lower Rhine Basin. In the course of modelling such large geological objects, substantial amounts of raw and model data of some geometrical and topological complexity are generated, which have to be managed adequately. It is essential to provide efficient interoperability between modelling tools and a database supporting higher dimensional spatial access to stored geological objects. Object oriented modelling techniques appear to be a convenient communication basis for geoscientists and computer scientists, because a direct analogy of the conceptual hierarchy of real geo-objects can be established with the object oriented database representation (Breunig et al., 2002).
Three-dimensional geometric models of specific geological objects are based on conceptual process models of generic classes of geological objects. The observed supporting data normally are sparse, compared to the complexity of the objects and their geological history. Moreover, the patterns of geological facts can only be interpreted if the geologist experiments with alternative process-oriented hypotheses in mind how the structures may have developed, establishing the best fit of ideas and data. Using computer aided design methods when making geometric models in geology ensures spatial consistency of the structural framework of geological surfaces and bodies. Such consistent three-dimensional models (Klesper, 1994) of geological objects define the present-day boundary conditions for subsequent backward reconstructions to access paleogeological states, so time is coming in as fourth dimension. A study of the Bergheim open pit lignite mine (Fig. 1) at the north- 


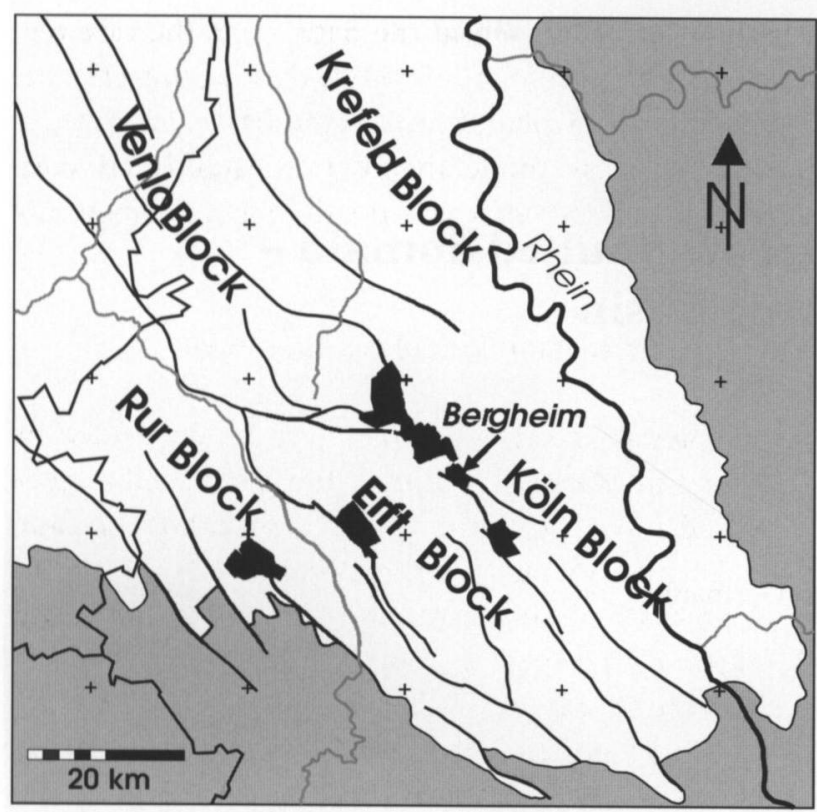

Fig. 1. Position of the Bergheim mine in the Lower Rhine Basin. Grey: basement of Rhenish Massif, stippled: open pit lignite mines.

eastern margin of a larger area modelled by Jentzsch \& Siehl (2002) aims at the construction of a kinematic model of a typical small faulted domain with detailed spatial information on strata and fault geometry. The objective is to learn more about the characteristic mechanical behaviour of the graben infill which could be upscaled to the structural development of a larger area within the rift system. For this purpose a new method for balanced volume-controlled 3D-restoration of a system of independent fault-delimited volume blocks is developed, that permits relative displacements of blocks at faults without affecting internal consistency.

The methods used in the Bergheim study for a balanced kinematic restoration and visualization are different from those applied in earlier studies (Alms et al., 1998; Jentzsch \& Siehl, 1999).

Instead of using a variant of the 'inclined shear' technique (White et al., 1986) for the restoration of geological sections or of stratum surfaces at a small number of listric normal faults, we model the balanced displacements of volume blocks delimited by more than hundred faults, controlled only by the geometric configuration of the study area, using Rouby's method of restoration in map plane (Rouby et al., 1996, 2000). For interactive modelling and for visualization no vertical exaggeration in scale is necessary, as lateral and vertical extensions are of the same order of magnitude.

\section{The data}

Open-pit lignite mines operated by the mining company Rheinbraun AG (Köln) have provided an excellent three-dimensional database in the southern part of the Lower Rhine Basin. It consists of well log information and in mining areas also of series of closely spaced detailed lithological cross-sections, designed by mining geologists and surveyors, available to us by courtesy of the company. The area studied in the Bergheim mine, has a size of $2 \mathrm{~km} \mathrm{x} 2 \mathrm{~km}$, with a relative depth of about $500 \mathrm{~m}$. The initial data of this study consist of a set of about 20 SW-NE-directed geological sections at a scale of 1:2000, arranged parallel to each other at distances of nearly $200 \mathrm{~m}$ (Fig. 2). There are approximately 130 faults to be included in the model as sliding surfaces. The fault pattern is modelled in detail to a depth of circa $500 \mathrm{~m}$. On such a small, near-surface, section, no listric form of the normal faults can be observed. Instead, in each section, most of the faults can be approximated by straight lines. The fault pattern in three dimensions, however, is quite intricate, whereas the sedimentary

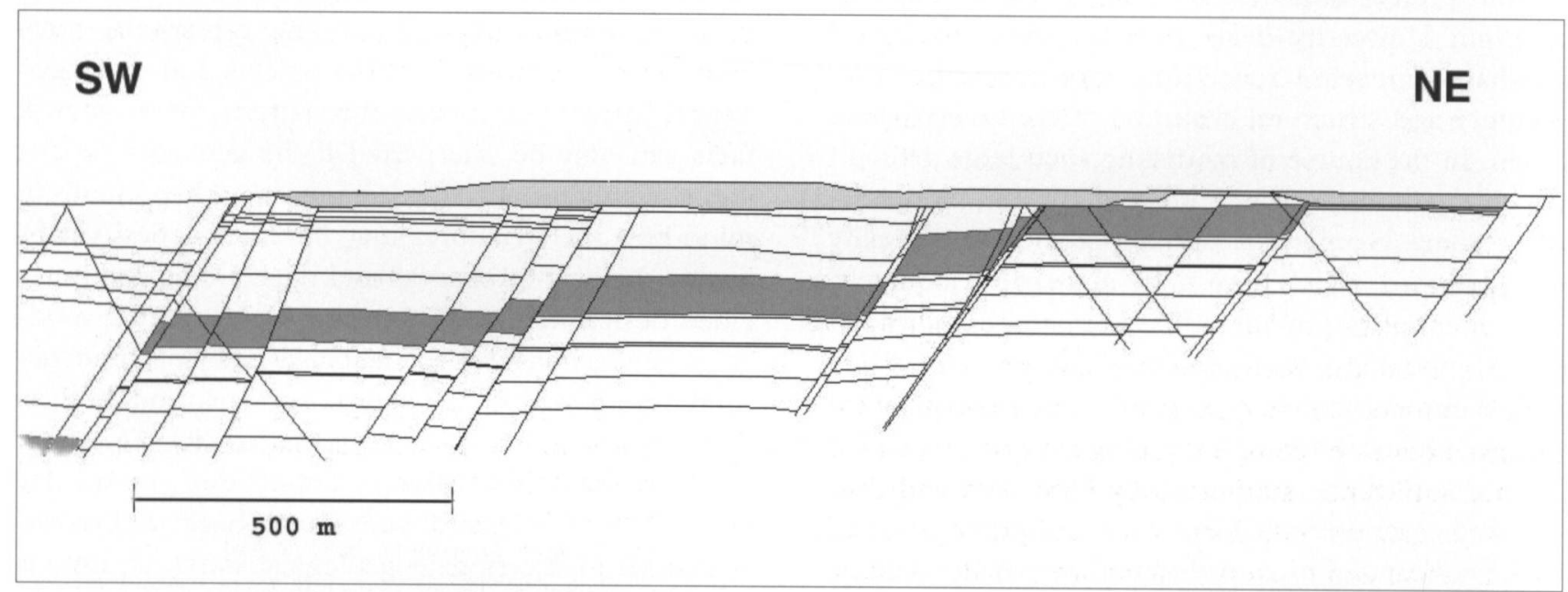

Fig. 2. One of the digitised cross-sections (Nr. 231) of the Mio-Pliocene strata of the Bergheim open pit mine. Light grey area indicates the refilled part of the mine, lignite seam 6 is marked dark grey. 
stratification between faults is rather regular, with the Upper Miocene main lignite seam of about $100 \mathrm{~m}$ thickness in the middle part of the sections.

The geological sections used as input data in this study are the most complete and reliable database available for this part of the Lower Rhine Basin. The underlying primary data derive from exploration wells and open pit mines, most of which are already exploited, refilled and recultivated, so they are not longer accessible. There is no seismic coverage of the area. The sections have been produced by various surveyors at different times and can be contradicting in some details, so they have to be adjusted for plausibility in the course of the three-dimensional reconstruction. It is therefore not possible to provide space-filling supporting primary data for the total 3D-model. Instead, we have to experiment with alternative process-oriented hypotheses of structural development to find the geologically most plausible solution, ensuring spatial consistency.

In the unconsolidated sediments only few indicative traces of details of the deformation kinematics are preserved. Observations at the exposed normal fault systems (Dethloff, 1993; Seidemann, 1993) document a relatively simple extensional regime, whereby a slight transtensional component (Plein et al., 1982; Klostermann, 1983; Schreiber \& Rotsch, 1998) cannot be excluded. GPS-measurements of the recent tectonic movements in the Lower Rhine Basin (Campbell \& al., 2002) indicate a horizontal extension in general east-west direction of up to $2 \mathrm{~mm} / \mathrm{a}$. Vertical subsidence amounts to at least $2 \mathrm{~mm} / \mathrm{a}$, as can be concluded from an earlier geodetic survey before groundwater drawdown due to mine water drainage (Quitzow \& Vahlensieck, 1955).

Because a priori knowledge of the displacement field of the faulted blocks is only approximative, we try to conclude the kinematic sequence of deformation from the geometrically possible backward restoration of the accumulated deformation pattern, taking compaction into account. The resulting sequence of block movements and deformations should represent the simplest pattern and should not contradict the criteria of a corresponding deformation field as mentioned above. From the analysis of the modelled displacement field we expect to gain additional insights into the structure-forming processes and their parameters. This type of procedure is typical for reconstructions of complex geological systems, which are not sufficiently supported by hard data and thus are underdetermined. There is no unique solution of such an inversion process; instead we usually obtain a set of approximately correct results. They can be evaluated on the basis of additional geological knowledge, which is not contained in the data - e.g. the rare displacement indications of single block movements. Taking the most plausible solution as initial stage of forward process modelling, better established constraints can be set as it was possible at the beginning of the study.

\section{Volume balanced restoration of the study area}

The geological sections of the study area provided by Rheinbraun AG are less than $500 \mathrm{~m}$ deep, and in general, fault lines can be considered as almost straight lines. Displacements along antithetic faults are almost negligible. Within each block, variations of depth and thickness of layers, and also the interior deformation of each horizon are small (tab.1, Fig. 3).

On the other hand, the number of faults is considerable, as is the number of resulting $3 \mathrm{D}$ blocks. As a

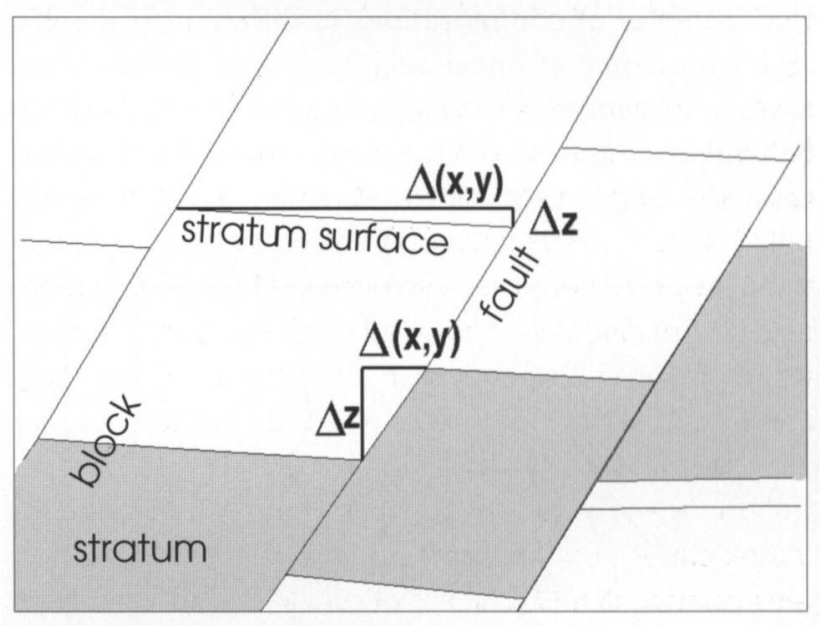

Fig. 3. Displacements measured along fault and dip of stratum surface within a block. $\Delta(x, y), \Delta z$ are the horizontal and vertical distances between corresponding points of a stratum surface on both sides of a block resp. fault.

Table 1. Differences in height along the hanging wall of coal seam 6 in section 231 (Fig.2) from SW to NE.

\begin{tabular}{lrrrrl}
\hline Type & $\mathrm{N}$ & $\Sigma \Delta(\mathrm{x}, \mathrm{y})$ & \multicolumn{1}{c}{$\Sigma \Delta \mathrm{z}$} & $\operatorname{Max} \Delta \mathrm{z}$ & $\operatorname{Max} \Delta \mathrm{z} / \Delta \mathrm{xy}$ \\
& & & & & \\
$\mathrm{F}$ & 6 & 356.0 & 455.6 & 119.4 & 2.58 \\
$\mathrm{~A}$ & 2 & 0.7 & -0.8 & -0.1 & -1.0 \\
$\mathrm{~S}_{\mathrm{NE}}$ & 11 & 1259.0 & -56.1 & -10.1 & -0.13 \\
$\mathrm{~S}_{\mathrm{SW}}$ & 8 & 400.4 & 16.6 & 9.3 & 0.08 \\
\hline
\end{tabular}

Legend (cf. fig.3):

Type of faults: F: synthetic, A: antithetic

Type of layer surfaces: $S_{\mathrm{NE}}$ : dipping in $\mathrm{NE}$ direction, $\mathrm{S}_{\mathrm{SW}}$ : dipping in SW direction

$\mathrm{N}$ : number of items

$\Sigma \Delta(\mathrm{x}, \mathrm{y})$ : sum of horizontal distances [m]

$\Sigma \Delta z$ : sum of vertical distances $[\mathrm{m}]$ at fault/within block

Max $\Delta z$ : maximal value of $\Delta z[\mathrm{~m}]$ at fault/within block

$\operatorname{Max} \Delta z / \Delta x y:$ maximal value of $\Delta z / \Delta(x, y)$ 
consequence, the $3 \mathrm{D}$ fault pattern is intricate. Moreover, our aim is to investigate $3 \mathrm{D}$ displacements rather than movements constrained to geological sections. The chosen reconstruction method therefore is based on relative movements at discontinuities of a large number of blocks.

\section{Outline of the $2 \mathrm{D}$ case}

Before discussing the 3D restoration, let us first consider movements constrained to be parallel to $2 \mathrm{D}$ sections. Within each section, rigid body movements of each block along the synthetic fault lines can be assumed in first approximation, which obviously preserve area respectively volume, but result in small gaps and overlaps at block borders. For each block there is one degree of freedom of movement, which for a given time step is uniquely determined by the reconstruction of the corresponding horizon. The result is a sequence of configurations at different time steps and a sequence of linear relative displacements from the actual geometry. These movements then have to be composed into a consistent sequence, which in this case is a simple task. As for every block, the amount and direction of displacement varies from one geological section to the next, linear interpolation of the displacement vector can be used, resulting in a shear which leaves the block volume unchanged, implying, however, a deformation of the 3D-blocks. If the remaining small differences in height within the reconstructed layer surface are to be equalised, a shear may also be applied to each block prior to block displacement. For an area-balanced reconstruction of a geological section, we need to deform the individual sections of different strata according to a compaction model, using a similar approach as applied by Jentzsch \& Siehl (2002).

\section{Determination of horizontal displacements in 3D using Rouby's method}

Instead of a balanced restoration in parallel vertical planes with essentially only one degree of freedom for a given shear method, our aim is to determine more general movements in 3D. This is achieved using Rouby's method (Rouby et al., 1996, 2000) of balanced restoration in the map plane. The method proceeds in several steps (Figs 4 \& 5).

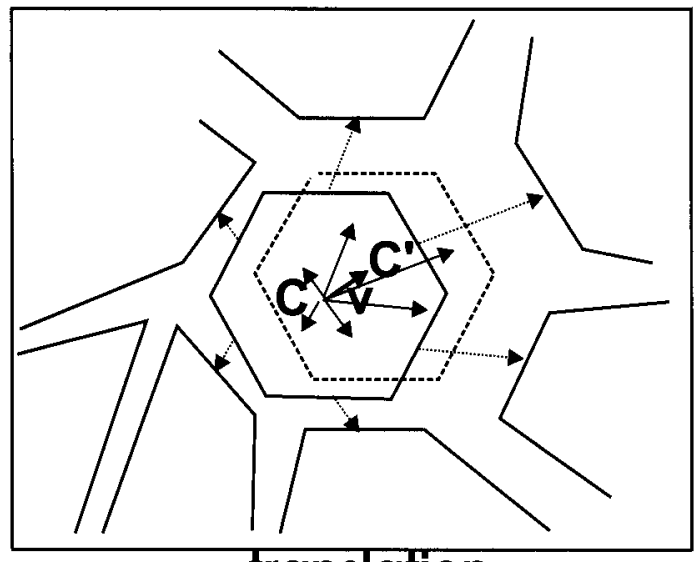

franslation

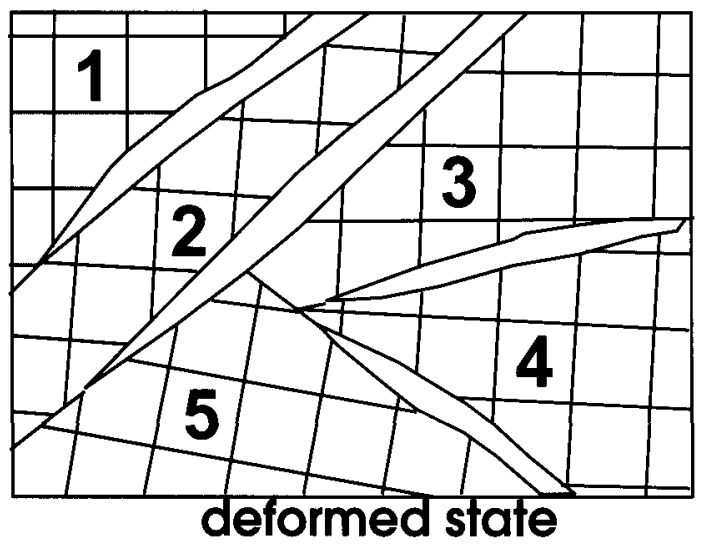

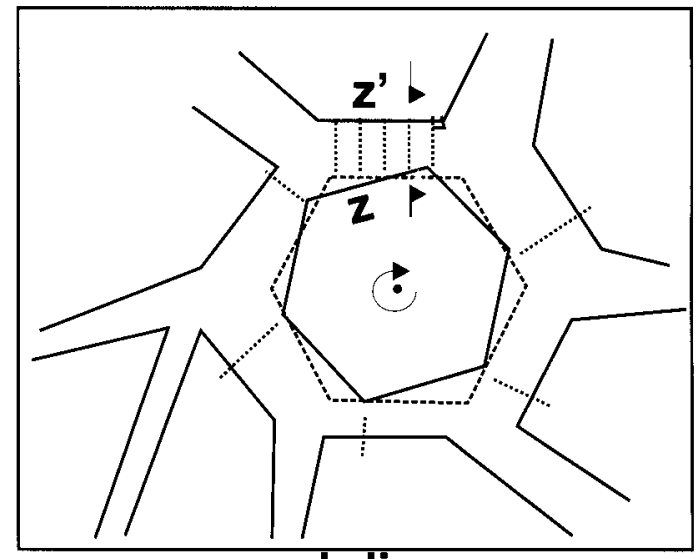

rotation

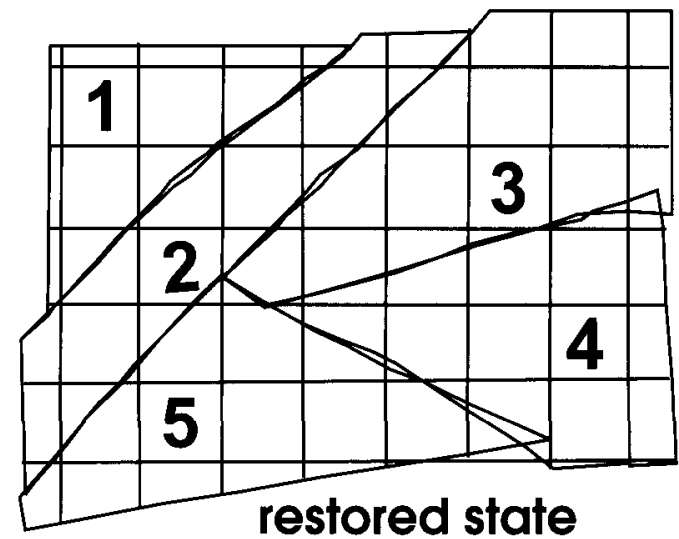

Fig. 4. Rouby's method of restoration in the map plane (adapted from Rouby et al.,1996). The centre of gravity c of a block is shifted and the block is rotated clockwise such as to minimise the sum of squared distances between neighbouring block boundaries $\mathrm{z}$ and $\mathrm{z}$ '. 
To restore the top stratum surface, the vertical component of a displacement field is determined by moving the points of the surface into the map plane $(z=$ 0 ), either by a vertical translation, or, if necessary, by vertical or by homogeneous shear with given azimuth and dip. Due to the small amount of variation of dip and thickness of strata (cf. tab.1.), in the Bergheim block-faulting model a special unfolding step does not seem to be necessary, in contrast to the case investigated by Rouby et al. (2000) in the Niger Delta area.

By a sequence of translations and rotations, the surface patches in the map plane are displaced in such a way, that the sum of squares of all gaps and overlaps between neighbouring patches attains a minimum. This problem of non-linear optimisation is approximately solved by an iteration method, and the outcome depends on the initial configuration, the number of iterations, a threshold value, and the order of steps. The result is a horizontal displacement field for each block (Fig.5).

The horizontal vector field is combined with the initial vertical component, and the resulting 3D-displacement field is projected onto the subsequent horizons within each block. The resulting movement is equivalent to a combination of rotation, translation, and shear, and can be applied to all points of the model, using interpolation where necessary.

In order to eliminate the remaining (minimal) gaps and overlaps, the patches may be subjected to a certain deformation, which is bound to leave the average area of the stratum top surface constant. Whereas the other operations do not affect the volumes of blocks or of parts of strata within blocks respectively, this operation has to be monitored in order to keep the area of the respective stratum boundary surface of each block constant.

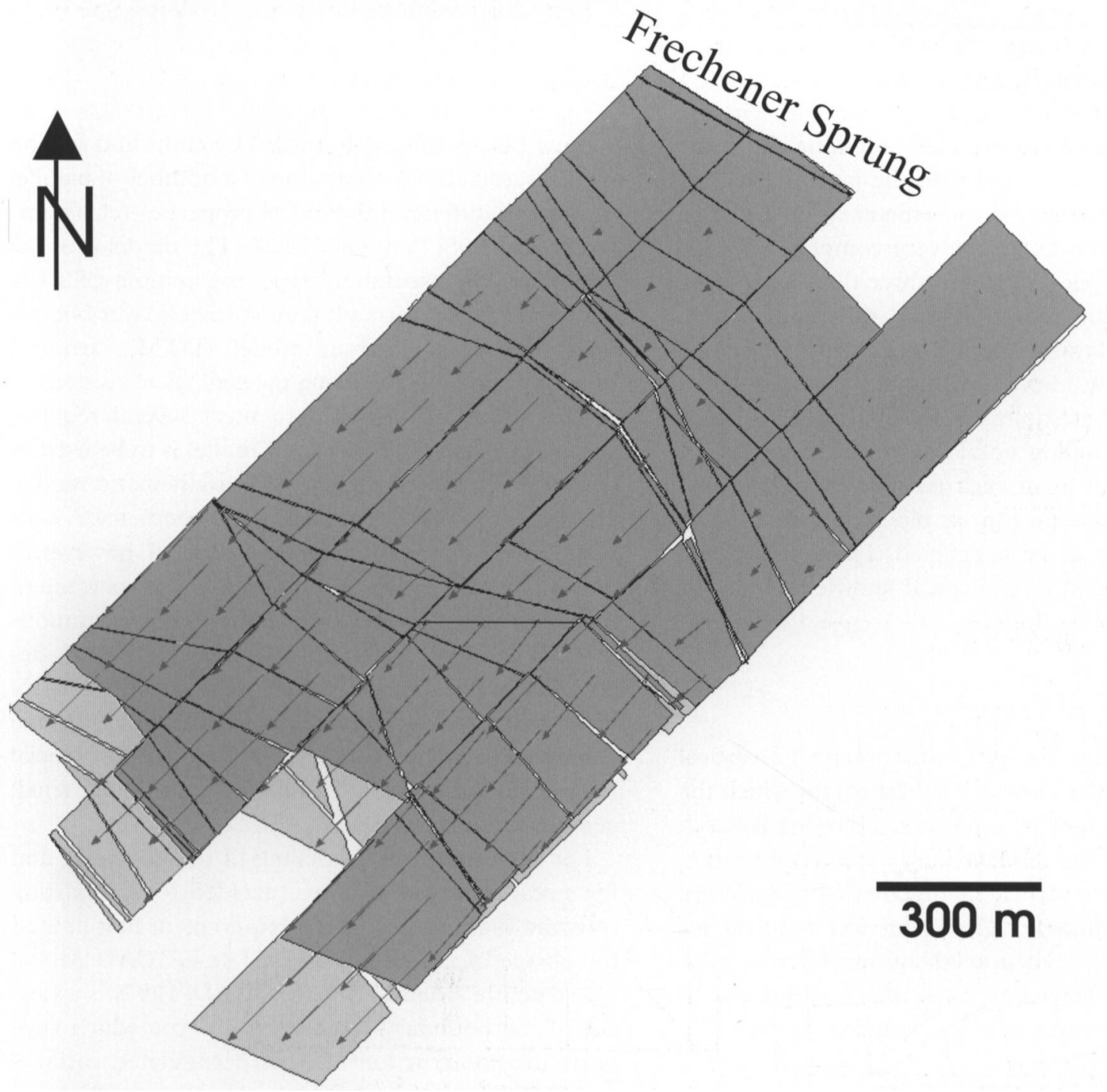

Fig. 5. Rouby's method of restoration in the map plane, applied to part of footwall of stratum 6 , the main lignite seam of Bergheim mine. Arrows mark the displacement vector field. The restored configuration is coloured dark grey. Near the SW corner the present-day position of blocks is visible in light grey. Two small blocks at the $\mathrm{N}$ adjacent to the fault 'Frechener Sprung' were kept fixed during restoration. 


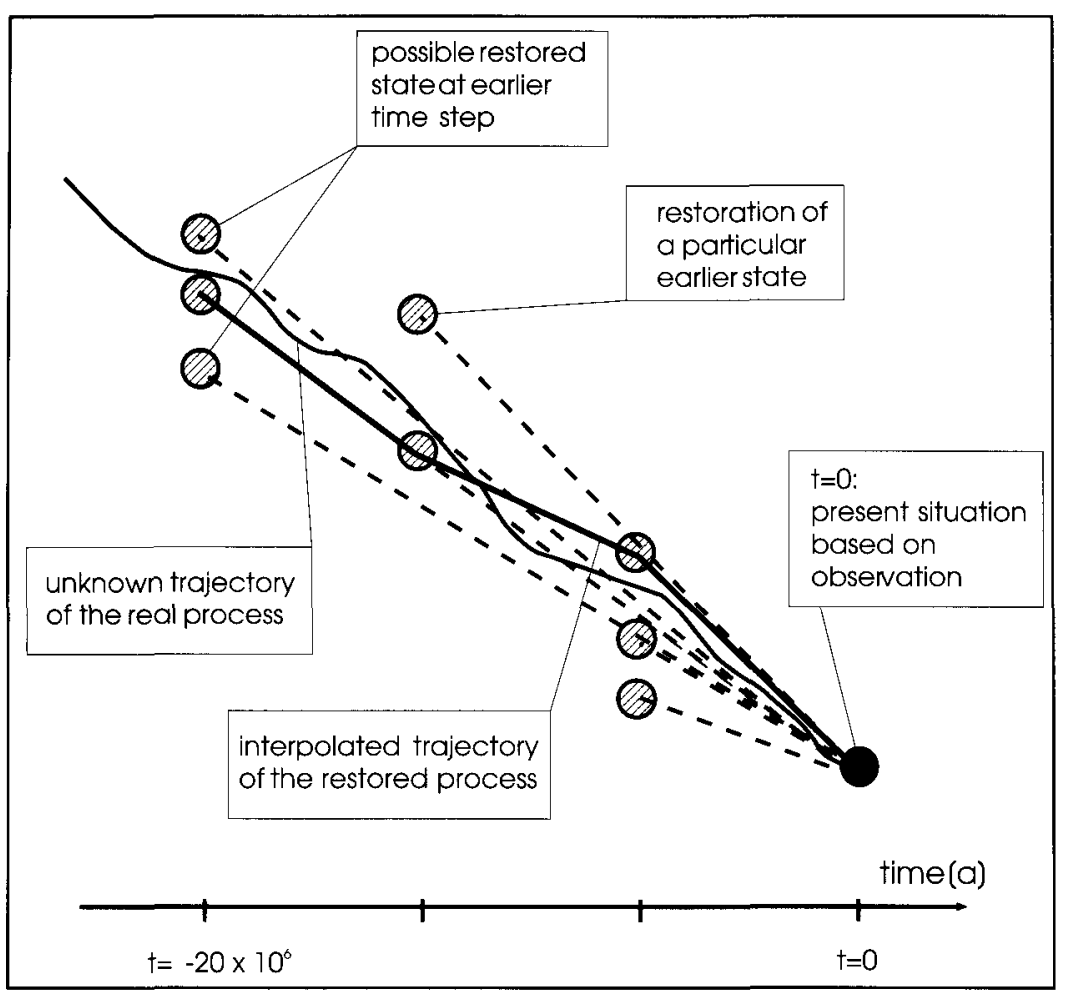

Fig. 6. Combining different stages of backward restoration of strata into a coherent sequence of movements to obtain a plausible approximation of the unknown true path.

Once possible restorations of individual horizons are determined, we are left with the task to combine them into a sequence of movements (Fig. 6). This task may well turn out to be very complex since we are dealing with movements in three dimensions and Rouby's algorithm may well yield different possible approximate solutions for each horizon. However, Rouby et al. (2000) have shown that the resulting displacement fields are quite stable with regard to variations of the preceding unfolding mechanism, e.g. of shear dip, as well as of such parameters of the map plane restoration algorithm as block cuts and choice of starting block to be kept fixed. The solution will imply consideration of geological knowledge not initially included in the data.

\section{Compaction}

For each block and for every time interval, a vertical section through the block is established, for which the effects of compaction are calculated, following Jentzsch \& Siehl (1999). In this particular case, compaction simply results in a vertical contraction of a block and its layers through time. A problem will occur at inclined fault planes, when neighbouring layer sections show different compaction rates, which may result in inconsistent deformations of the boundary surfaces.

\section{The 3D-geometry model}

The geometry model consists of a large number of volume blocks (Fig. 7) bordered by faults and section surfaces, each block consisting of a number of parallel strata with different lithological properties (cf. Thomsen et al., 1998; Pongratz, 1999). The model is of the 'boundary representation' type, the volume cells being delimited by parts of: fault surfaces, layer boundaries and digital terrain model (DTM), artificial boundaries mostly following the geological sections.

This model was chosen to meet several requirements: The static 3D-geometry model is to be used as the basis for the construction of a kinematic model, and thus of a time-dependent $3 \mathrm{D}(\mathrm{t})$-geometry. A consistent mesh comprising the whole model, however, is not appropriate, as any discontinuity of displacement inevitably results in the destruction of the continuous mesh. Therefore, a system of independent fault-delimited volume blocks is built, that permits relative displacements of blocks without affecting internal consistency. At the contacts of these blocks special fault objects are used to handle the unavoidable small geometrical inconsistencies.

For the interactive modelling of the geometry and for storage and retrieval, we decided to use existing software as far as possible, a requirement that limited the choice of meshing models. The GOCAD Model 3D structure (Mallet, 1992; GOCAD, 1997) is a variant of the boundary representation type which supports the construction of both triangulated surfaces and block volumes and also checks of internal consistency of each block during the interactive building of the model. In addition, the GOCAD data format pro- 


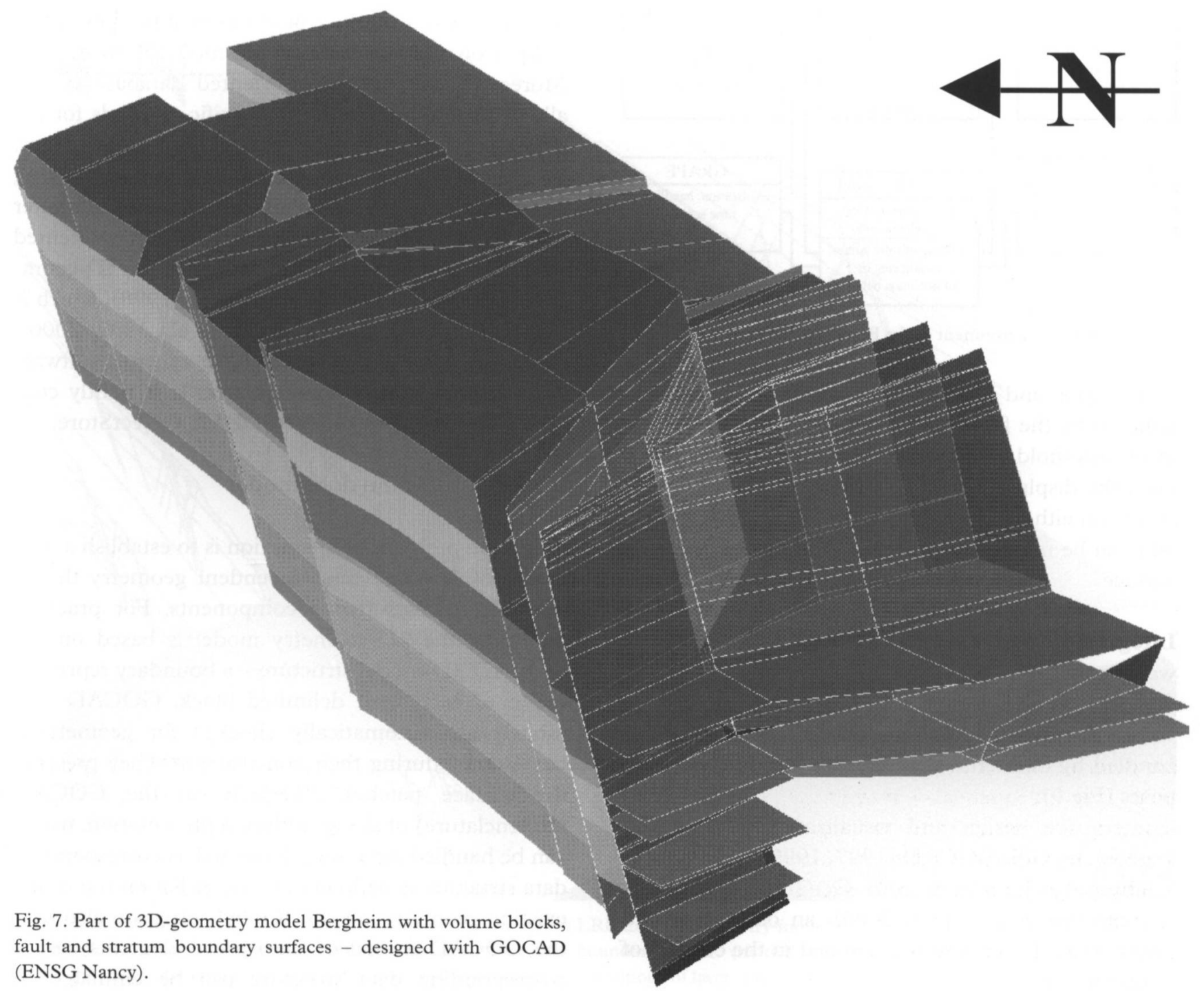

vides a straightforward data interface to Rouby's algorithm (Rouby et al., 1996) for the restoration in the map plane.

\section{Modelling faults by a new object class}

As we design a balanced kinematic 3D-model, the following problem arises: the consistency of the meshing of a 3D-model built of blocks which are separated by

single fault surfaces is destroyed by the slightest relative displacement of neighbouring blocks. For continuous movements, there is no way to avoid such inconsistencies, because the mesh that defines the internal topology of a triangulated surface is a discrete structure that can only be modified stepwise, but not continuously. The only possible way to overcome this problem is to control the resulting errors. For this purpose, fault discontinuities are modelled as distinct objects (Fig. 8).

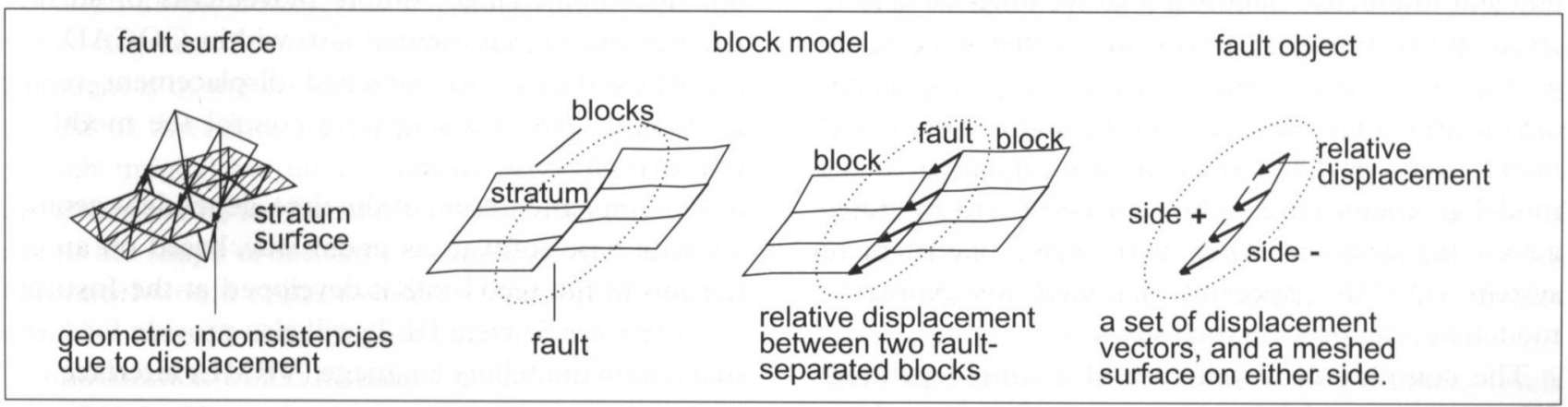

Fig. 8. A fault object is inserted between 3D-blocks to take care of geometrical inconsistencies at block borders, caused by timedependent continuous displacements of discretised surfaces. 


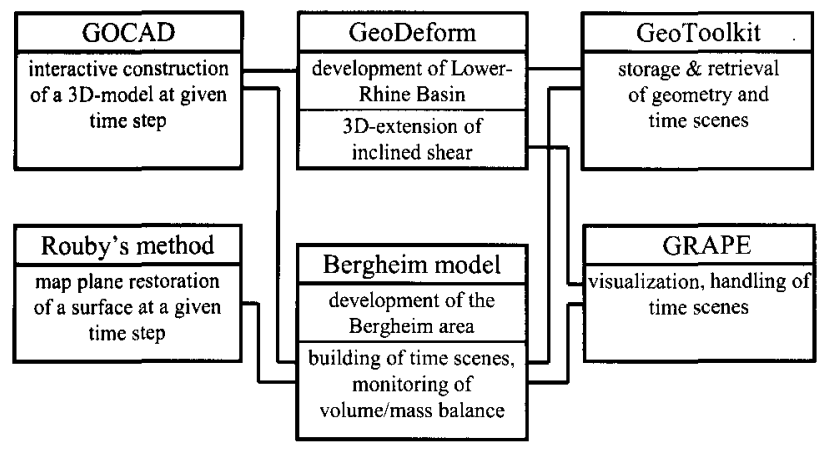

Fig. 9. Software environment of the Bergheim model.

Any gaps and overlaps at faults are detected and handled by the fault object, which must monitor if a given threshold is exceeded. As an additional advantage, the displacement between pairs of homologous points on either side of the fault is modelled explicitly and can be made visible as a vector field on the fault surface.

\section{Integration with GeoToolKit and different soft- ware tools}

In the Bergheim study, the same geometry model is handled by different software tools for different purposes (Fig.9):

- interactive design and visualization of the 3Dgeometry with GOCAD $(1997,1999)$,

- storage and retrieval with GeoToolKit/GeoStore

(Balovnev et al., 1997, 2000), an object-oriented geometry database tool developed in the context of Breunig et al. (2002),

- balanced restoration with own software and with Rouby's program (Rouby et al., 1996),

- animation with GRAPE (1997).

These components are from different sources and use the GeoToolKit geometry database for storage and retrieval of geometry objects.

\section{Why an object-oriented geometry database?}

The entire $3 \mathrm{D}(\mathrm{t})$-geometry model will be too big for efficient interactive handling - so we must be able to store and to retrieve parts of the model selected on geometrical and geological criteria. A larger geological model should also allow for shared access by different users via network. Changes (updates) to the model geometry have to be kept consistent by transaction management. Only a database management system (DBMS), specially designed for geometric modelling, can provide such services.

The complex data structure of a time-dependent 3D-geometry model, however, cannot be mapped onto a traditional relational data model without a lot of overhead and a number of workarounds, if no information on the structure of the model is to be lost. Moreover, only an object-oriented database system allows for the integration of specific methods for the handling of 3D-geometry and of time dependency. Therefore, in close co-operation with the working group of A.B. Cremers at the Institute of Computer Science III of Bonn University, an object-oriented software for the storage and retrieval of the 3D-geometry has been developed (Alms et al., 1998), which is based on GeoToolKit (Balovnev et al., 1997, 2000). GeoToolKit provides a set of object-oriented software tools for spatial data maintenance. It is tightly coupled with the object-oriented DBMS ObjectStore.

\section{Portable common data model}

The main problem of integration is to establish a data model of 3D- and time-dependent geometry that is portable to all software components. For practical purposes, the 3D-geometry model is based on the GOCAD 3D-model structure - a boundary representation of each fault delimited block. GOCAD 3Dmodels are automatically checked for geometrical consistency during their construction. They preserve the surface patches ('TFACE' in the GOCAD nomenclature) of the boundary representation, which can be handled separately, if needed. A corresponding data structure is defined in GeoToolKit on top of the existing geometry classes. Rouby's program also uses the GOCAD format of the surface elements, and a corresponding data structure can be emulated in GRAPE (1997). The representation of faults as separate entities, sharing boundary surfaces with blocks, is an extension to the possibilities of GOCAD, but uses GOCAD triangular meshes as components.

For the representation of time-dependent objects, we use a time scene tree following Polthier \& Rumpf (1995) and GRAPE (1997). Such a data structure supports a flexible handling of changes of the mesh through time. The GRAPE software is also used for the visualization of movements. As long as the meshing does not change, simple movements of surface patches can be represented also within GOCAD, using 3D-surfaces with attached displacement vector fields and GOCAD scripts to control the modification of point coordinates.

The implementation of the time-dependent geometry data base software is under way, based on an extension of the GeoToolKit developed at the Institute of Computer Science III. It will also provide for a virtual reality modelling language (VRML) interface. 


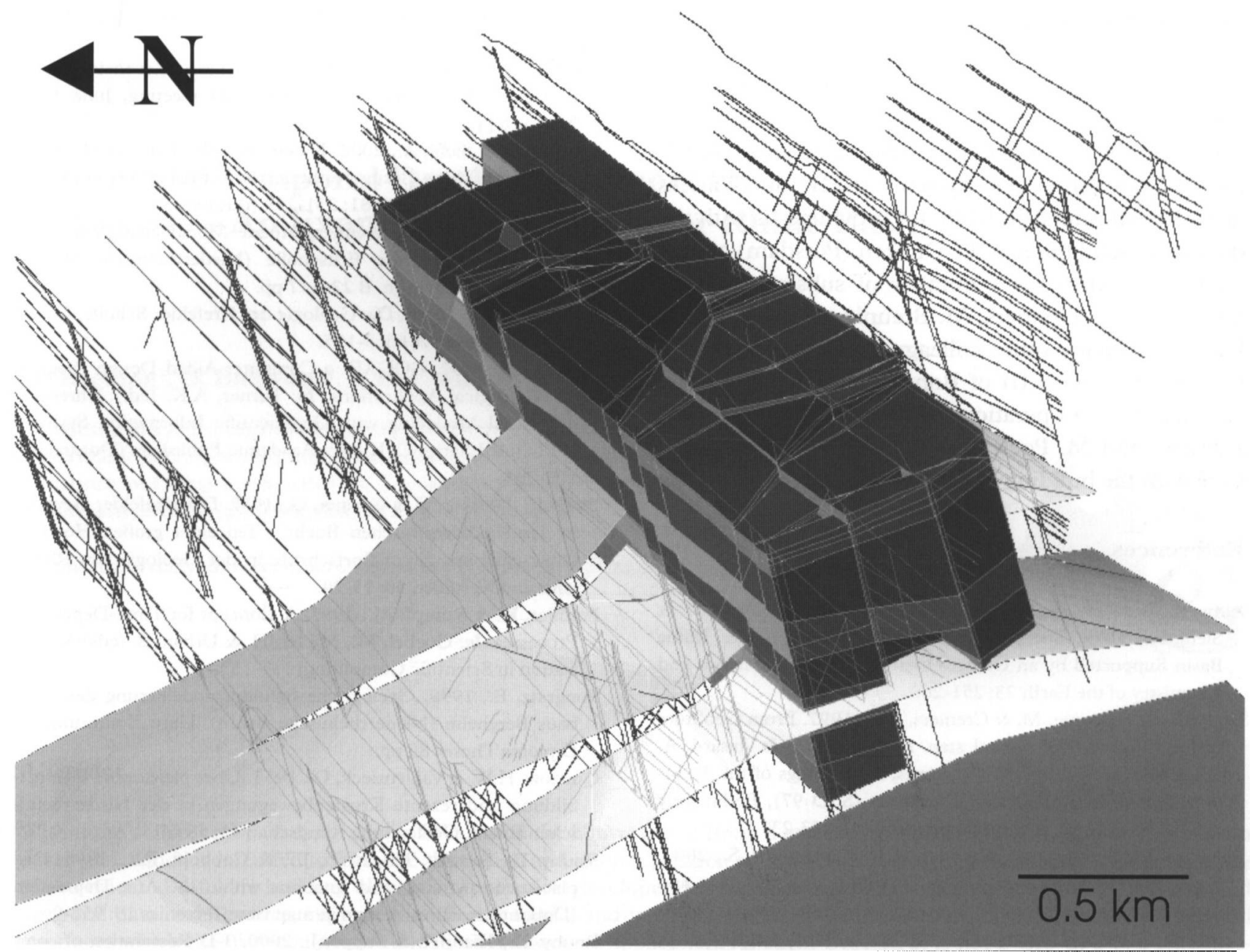

Fig. 10. Embedding of part of the geometry model of the southern LRB into the geometry model 'Tagebau Bergheim'. Both volume blocks and profile cross-sections at scale 1:2000 and a scaled down layer boundary surface (modelled at scale 1:250000) are displayed. Near the centre the different amounts of detail of faults as well as differences of positions of layer surfaces are visible.

\section{Outlook: possible extensions of the present study}

The present geometry model may serve as a base for a numerical model using a 3D-extension of Waltham's method. Waltham (1989) showed that the problem of an area-balanced restoration of a $2 \mathrm{D}$-geological section can be reformulated as solving the continuity equation for a displacement field with appropriate initial and boundary conditions. This differential equation alone, however, is not sufficient to account for all degrees of freedom of the problem. To achieve uniqueness of the solution, the geologist must supply a field of directions of displacements. A similar approach might be used for an extension of the Bergheim study, as the method makes no assumption about the shape of the fault surfaces. Such a numerical model would require solving a partial differential equation for each fault-delimited block.

The solution would be balanced and smooth within each block. However, it would still not model any forces applied, nor any mechanical property of the strata considered. These would only be taken into account by a numerical model of the dynamics of basin development, the discussion of which is beyond the scope of the present paper. However, the kinematic model established by empirically backward restoring earlier configurations may serve to gain some insight into the stress field, and to help to define suitable initial configurations and constraints for dynamical forward modelling.

The Bergheim model is one of two alternative approaches to the problem of a balanced restoration at different scales; the other one is the model of the Lower Rhine Basin by Jentzsch \& Siehl (2002). Besides the question of compatibility of the two geometries and of the solutions found by different methods at different scales, the interesting data modelling problem arises, how different versions of the same abstract geometrical object (volume block, stratum surface) should be handled, representing different levels of generalisation (Fig. 10). 


\section{Acknowledgements}

This work was supported by DFG (Deutsche Forschungsgemeinschaft) within the Collaborative Research Centre 'Interactions between and Modelling of Continental Geo-Systems' (SFB 350). Thanks go to Rheinbraun AG, Köln, for providing us with the data and useful hints, to O. Oncken (Potsdam) and A. Henk (Freiburg) for a number of substantial comments, to A.B. Cremers, M. Breunig, S. Shumilov, B. Koos, and many other colleagues of the Institute of Computer Science III of Bonn University for a long and fruitful co-operation, and to E. Pongratz, $M$. Ruesgen and M. Poelchau (Bonn) who spend much time with the building of the $3 \mathrm{D}$-geometry model.

\section{References}

Alms, R., Balovnev, O., Breunig, M., Cremers, A.B., Jentzsch, T. \& Siehl, A., 1998. Space-Time Modelling of the Lower Rhine Basin Supported by an Object-Oriented Database. Physics and Chemistry of the Earth 23: 251-260.

Balovnev, O., Breunig, M. \& Cremers, A.B., 1997. From GeoStore to GeoToolKit: The second step. In: Scholl, M. \& Voisard, A. (eds): Advances in Spatial Databases, Proceedings of the $5^{\text {th }}$ Intern. Symposium on Spatial Databases (SSD 97), Berlin, July 1997, LNCS 1262. Springer Verlag (Berlin): 223-237.

Balovnev, O., Breunig, M., Cremers, A.B. \& Shumilov, S., 2000. Extending GeoToolKit to Access Distributed Spatial Data and Operations. In: Proc. of $12^{\text {th }}$ International Conference on Scientific and Statistical Database Management, Berlin, June 2000.

Breunig, M., Balovnev, O., Cremers, A.B. \& Shumilov, S., 2002. Spatial and Temporal Database Support for Geologists - An Example from the Lower Rhine Basin. Netherlands Journal of Geosciences / Geologie en Mijnbouw 81: 251-256 (this issue).

Campbell, J., Kümpel, H.-J., Fabian, M., Fischer, D., Görres, B., Keysers, C.J. \& Lehmann, K., 2002. Recent movement pattern of the Lower Rhine Basin from tilt, gravity and GPS data. Netherlands Journal of Geosciences / Geologie en Mijnbouw 81: 223-230 (this issue).

Dethloff, R., 1993. Untersuchungen und Modellrechnungen zur tektonischen Entwicklung im Gebiet des Tagebaus Bergheim (MittlererVillerücken/Niederrheinische Bucht). Univ. Bonn, unpubl. Diploma Thesis: $171 \mathrm{pp}$.

GOCAD (1997): GOCAD++1.4 User's Manual. ASGA, ENSG Nancy.

GOCAD (1999): GOCAD Tech. Documentation, http://www.ensg.u-na.ncv.fr/GOCAD.

GRAPE (1997): GRAPE - GRAphics Programming Environment
- Manual: 382 pp., Version 5.3 (http://www.iam.unibonn.de/sfb256/grape).

Jentzsch, T. \& Siehl, A., 1999. From Palinspastic Reconstruction to Kinematic Basin Models. $19^{\text {th }}$ GOCAD meeting, June 1999 , Nancy: $6 \mathrm{pp}$.

Jentzsch,T. \& Siehl, A., 2002. Kinematic subsidence modelling of the Lower Rhine Basin. Netherlands Journal of Geosciences / Geologie en Mijnbouw 81: 231-239 (this issue).

Klesper, C., 1994. Die rechnergestützte Modellierung eines 3DFlächenverbandes der Erftscholle (Niederrheinische Bucht). Berliner Geowiss. Abh. B 22: 117 pp.

Klostermann, J., 1983. Die Geologie der Krefelder Scholle. Geologisches Jahrbuch A 66: 3-115.

Mallet, J.L., 1992. GOCAD: a Computer Aided Design Program for Geological Applications. In: Turner, A.K. (ed.): Three-Dimensional Modelling with Geoscientific Information Systems. NATO ASI Series C. Kluwer Academic Publishers (Dordrecht): 123-141.

Plein, E., Dörholt, W. \& Greiner, G., 1982. Das Krefelder Gewölbe . in der Niederrheinischen Bucht - Teil einer großen Horizontalverschiebungszone? Fortschritte in der Geologie von Rheinland und Westfalen 30: 15-29.

Polthier, K. \& Rumpf, M., 1995. A Concept for Time-Dependent Processes. In: Goebel, M., Müller, H. \& Urban, B. (eds): Visualization in Scientific Computing: 137-153.

Pongratz, E., 1999. Geologische Strukturmodellierung des Tagebaus Bergheim (Niederrheinische Bucht). Univ. Bonn, unpubl. Diploma Thesis: 85 pp.

Quitzow, H.W. \& Vahlensieck, O., 1955. Über pleistozäne Gebirgsbildung und rezente Krustenbewegungen in der Niederrheinischen Bucht. Geologische Rundschau 43: 56-67.

Rouby, D., Souriot, Th., Brun, J.P. \& Cobbold, P.R., 1996. Displacements, strains, and rotations within the Afar Depression (Djibouti) from restoration in map view. Tectonics 15: 952-965.

Rouby, D., Xiao, H. \& Suppe, J., 2000. 3-D Restoration of complexly folded and faulted surfaces using multiple unfolding mechanisms. American Association of Petroleum Geologists Bulletin 84: 805-829.

Schreiber, U. \& Rotsch, S., 1998. Cenozoic block rotation according to a conjugate shear system in Central Europe - indications from palaeomagnetic measurements. Tectonophysics 299: 111-142.

Seidemann, R., 1993. Untersuchungen zur Tektonik der Niederrheinischen Bucht. Univ. Bonn, unpubl. Diploma Thesis: 246 pp.

Thomsen, A., Jentzsch, T. \& Siehl, A., 1998. Towards a balanced Kinematic Model of a Faulted Domain in the Lower Rhine Basin. GOCAD ENSG Conference on 3D Modelling of Natural Objects: A Challenge for the 2000's, June 1998, Nancy: 12 pp.

Waltham, D., 1989. Finite Difference Modelling of Hangingwall Deformation. Journal of Structural Geology 11: 433-437.

White, N., Jackson, J.A. \& McKenzie, D. P., 1986. The Relationship between the Geometry of Normal Faults and that of the Sedimentary Layers in their Hanging Walls. Journal of Structural Geology 8: 897-909. 